\title{
Developing a Creative-Cognitive Model of Entrepreneurial Alertness to Business Opportunities
}

\author{
Vesa Puhakka \\ Department of Management, Oulu Business School, University of Oulu \\ PO box 4600, 90014 University of Oulu, Finland \\ Tel: + 35-88-553-2946Ｅ-mail: vesa.puhakka@oulu.fi
}

Received: June 19, 2011

Accepted: July 20, 2011

Published: December 15, 2011

doi:10.5430/jms.v2n4p85

URL: http://dx.doi.org/10.5430/jms.v2n4p85

\begin{abstract}
A creative-cognitive perspective is used in this study to explore alertness to business opportunities in order to develop a model of business opportunity recognition. It is assumed that the elements constituting this opportunity creation are entrepreneur's creative cognitive process, internal creative qualities, environmental conditions supporting or hindering creativity and interaction of these elements, and that they have a significant impact on the innovativeness of the business opportunity. Through the development of the model an aim is made to clarify why some entrepreneurs create novel ideas while others just copy the old and used ones.
\end{abstract}

Keywords: Entrepreneurship, Business Opportunity, Alertness, Creativity, Cognitive

\section{Introduction}

Kaish and Gilad (1991) already indicated the ability to recognize business opportunities to be dependent on skills to perceive relevant information from markets. They argued that entrepreneurs recognize business opportunities by gathering information from multiple sources and interpreting it with fluency. This empirical finding is based on the seminal theory on entrepreneurial alertness by Kirzner (1979, 1981, 1997). He has presented that entrepreneurs are alert to business opportunities existing in markets because of their skills to interpret and exploit market information. In spite of the importance of the theory on entrepreneurial alertness by Kirzner and efforts to empirically confirm it by Kaish and Gilad (1991), much remains to be done to understand the phenomenon. For example, Gaglio (2004) demonstrated that as a phenomenon alertness to opportunities is complex and needs more extensive research to deepen the understanding of it.

Entrepreneurial alertness to opportunities is an interesting issue, since it has become an important part of a considerable amount of entrepreneurship research (e.g., Anokhin, Wictor \& Autio, 2009; Baumol, 1993; Carree \& Thurik, 1994; Cheah, 1990; Cooper, Folta \& Woo, 1995, Hebert \& Link, 1988; Shane \& Venkataraman, 2000). The research has displayed that alertness to business opportunities is an important part of the entrepreneurial process of initiating new businesses (Bygrave, 1993) and thus a deeper understanding of it is valuable. Even though business opportunities have been seen as important to study, the theoretical and empirical elaboration of the phenomenon is still in its infancy (Gaglio, 2004; Gaglio \& Katz, 2001). Therefore, it is not surprising that the knowledge is undeveloped. One of the most urgent problems to be solved is the lack of a psychologically rooted theoretical model for empirical probing. Until now the theory on alertness to business opportunities has been based more on economic theories than behavior of an entrepreneur. This gap in the understanding of an essential part of entrepreneurship, namely entrepreneurial alertness to business opportunities, suggests that both theoretical and empirical modeling of the phenomenon is needed.

The objective of present study is to deepen our knowledge by developing a creative-cognitive model of entrepreneurial alertness to business opportunities. This objective is sought by combining research on entrepreneurship and entrepreneurial alertness, cognitive psychology on heuristics and creative behavior of individuals. The research problem can be stated in the form of the following question: What is entrepreneurial alertness to business opportunities from the point of view of individual cognitive creativity? To answer this question the study is built upon three sub-problems: What is entrepreneurial alertness to business opportunities? How do entrepreneurs process cognitively business opportunities? Why do entrepreneurs want to comprehend their creativity by recognizing business opportunities?

Answers to the above are to be reached by proceeding as follows: First, entrepreneurial alertness to business 
opportunities is examined to answer the first sub-problem. Second, research on cognitive behavior and especially heuristics is illustrated with regards to answering the second sub-problem. Third, knowledge on creativity is introduced to answer the third sub-problem. Fourth, a theoretical model of entrepreneurial alertness to business opportunities is introduced to address the main research problem. Last, a discussion of the model in reference to the previous research on the subject is presented.

\section{Entrepreneurial Alertness to Business Opportunities}

According to Kirzner $(1979,1981,1997)$ entrepreneurial alertness refers to discovering business opportunities and utilizing resources to make use of these opportunities to create value. Kaish and Gilad (1991) found some empirical evidence for suggesting entrepreneurial alertness to be a practice of scanning an environment intensively and fluently in order to recognize business opportunities. Kirznerian entrepreneurship promotes changes within an existing situation by discovering profitable discrepancies, gaps and mismatches (Cheah, 1990). Bull and Willard (1993) have suggested that entrepreneurial alertness is a derivate of the definition of entrepreneurship by Schumpeter (1934). In this case entrepreneurial alertness is about discovering business opportunities which have more radical impact on a market-place. Baumol (1993) has widened the definition of entrepreneurial alertness by indicating that it refers to innovative, non-routine activity which involves instincts, hunches and inspiration (see also Gaglio \& Katz, 2001).

Hence, what is entrepreneurial alertness? First, it is being cognitively (mentally) open and ready for opportunities (Baron, 2004; Martello, 1994). Entrepreneurs constantly search and try to discover opportunities and are ready to take advantage of them. Thus, it is a question of mentally behaving in a certain way, i.e. cognitive style (Gaglio \& Katz, 2001). Second, some entrepreneurs are alert and some are not (Gaglio, 2004). Alert entrepreneurs have internal and external capabilities, i.e. intellectual and social capital, to be ready for opportunities. More importantly they are capable of transforming pieces of information into a concrete solution (Anokhin et al., 2009; Zahra, Korri \& Yu, 2005). Thus, it is also a question of capability of entrepreneurs. Third, the motivation of entrepreneurs to search for opportunities is supported or hindered by the environment (Shepherd \& DeTienne, 2005). If the environment does not socially support or teach entrepreneurially alert behavior, business opportunities will never be found. Thus, it is ultimately a question of environmental support. On the basis of the above, entrepreneurial alertness is seen in the present study as a cognitive mental process which is built upon the abilities of entrepreneurs and support of social and environmental conditions, which creates new solutions to business situations, and which comes to the fore as concrete and valuable business opportunities. Entrepreneurial alertness could be thus seen as behavior of an entrepreneur which realizes his/her entrepreneurship.

How does entrepreneurial alertness come into existence? Kaish and Gilad (1991) have suggested that Kirznerian entrepreneurial alertness is a consequence/corollary of business opportunities, and further entrepreneurship, by continual efforts to fulfill economic discontinuities. Thus, the alertness process is spontaneous discovering and acting on disequilibrium opportunities. On the other hand, the Schumpeterian view of alertness could be described as preparedness to opportunities by breaking the existing equilibrium situation. Thus, Schumpeterian alertness is also discovering and acting on opportunities. The difference is in the nature of the opportunity; the alertness process in itself is the same in both situations (Yu, 2001). The above discussion suggests that both of the most relevant theories of entrepreneurship (Cheah, 1990) understand entrepreneurial alertness as a mental process of entrepreneurs. Therefore, the present study sees entrepreneurial alertness as coming into existence by cognitive process in which the mental readiness of an entrepreneur is realized through discovering and acting on a business opportunity (Gaglio, 2004).

Why are entrepreneurs alert in the first place? Business opportunities are discovered by unique preparedness to recognize them. Entrepreneurially alert are those individuals who have the capability to understand which of the business opportunities are the most profitable when they come across them (Shepherd \& DeTienne, 2005). Therefore, it could be suggested that entrepreneurs are alert to business opportunities when they are mentally prepared and able to recognize profitable opportunities. This leads to the question of what is this unique preparedness and ability. In the present study these are seen to be a result of interaction between the internal qualities and environmental conditions of an entrepreneur. By this is meant that those entrepreneurs who are alert to profitable business opportunities have internal qualities, environmental conditions and interaction of these which supports this kind of mental activity. Next is discussed how and why entrepreneurs are alert to business opportunities.

\section{Cognitive Process of Being Alert to Business Opportunities}

Research on heuristics is part of cognitive psychology (Mayer, 1992). Heuristics are a part of studying the mental biases of individuals. This tradition is based on the seminal article by Tversky and Kahneman (1974). By heuristics they mean specific rules of thumb or intuitive guidelines which help to introduce solutions to uncertain problems (see also Kahneman, Tversky \& Slovic, 1982). In the above article they argue that in an informational complex world individuals 
must use simplified strategies (heuristics) for processing information cognitively. The world around us, according to Tversky and Kahneman (1974), is so rich that people have not had a chance to handle it all. Therefore, the human mind has simplified the situation and uses certain general strategies.

These strategies are a kind of decision rules about what to do in varying situations. By using these, individuals do not have to think so exhaustively. There is, of course, a danger in using these heuristics. It is possible that heuristics are not satisfactory or accurate. They could even be unwise. The result is that cognitive information processing is biased because individuals use these as mental short-cuts (Kahneman, 2003; Tversky \& Kahneman, 1971). However, heuristics are also very useful because situations are so complex. If the individual has sufficient experience and knowledge, it is possible that (s)he has very usable heuristics. Based on Tversky and Kahneman (1974), it is possible to suggest that heuristics strongly affect individual cognitive information processing, which is analogous with business opportunity identification.

Human beings have different kinds of heuristics (Oswald \& Grosjean, 2004). For example, Schneider (1995) presents two of them. According to him, people have a tendency to judge other people on the basis of how well they fit into known examples from the past. This heuristic could be called anchoring (cf. Busenitz \& Lau, 1996). This is normally a good heuristic because experience usually helps a lot, but it could also mislead. Another heuristic is availability. This means that we rely on those examples in memory for which we can find ready examples. Further, Busenitz and Barney (1997) put forward heuristics of representation and overconfidence. Representation means that people make generalizations based on only a few experiences (see also Bazerman, 1990; Nisbett \& Ross, 1980; Tversky \& Kahneman, 1971). In other words, if an individual has seen, for example, four white rabbits, (s)he could believe that all rabbits are white. Overconfidence, then, means that people see situations too optimistically (see also Fischoff, Slovic \& Lichtenstein, 1977). For example, it is possible that entrepreneurs create new ventures because they believe that the opportunities they see are real, even though the reality could be just the opposite.

Based on the above, it is proposed that because there are different kinds of entrepreneurs, they probably also have different kinds of heuristics. Further, if they have different heuristics and because heuristics determine their cognitive processes in uncertain situations, such as opportunity recognition, entrepreneurs have different types of opportunities. Busenitz and Barney (1997), for instance, have indicated that heuristics are cognitive decision making styles - rules and subjective opinions people use to depend on when making decisions. The heuristics of entrepreneurs direct how they gather and use information, and especially what they discover based on information (Busenitz \& Barney, 1997; Busenitz \& Lau, 1996; Krueger, 2005; Manimala, 1992; Palich \& Bagby, 1995). Manimala (1992), for instance, has indicated that entrepreneurs discover pioneering, high innovative businesses or more ordinary, low innovative businesses due their dissimilarity in heuristics. Busenitz and Lau (1996), in turn, have suggested that different kinds of businesses emerge primarily because entrepreneurs differ in heuristics. Further, in their study of heuristic differences between entrepreneurs and managers, Busenitz and Barney (1997) found entrepreneurs to behave differently than managers because of their heuristics. The heuristics they indicated as affecting behavior were overconfidence and generalizing. Based on the above, it is proposed in this study that the reason for different types of business opportunities is to be found in cognitive information processes, which come into the existence as different types of heuristics (Krueger, 2005).

Palich and Bagby (1995) have suggested that entrepreneurs may be as different from each other as they are from the rest of the population. This realization, and the lack of results from trait research in particular, has created the cognitive dimension of entrepreneurship (see Gaglio, 2004; Krueger, 2005). In their study, Palich and Bagby (1995) found that entrepreneurs do not feel that they take more risks than non-entrepreneurs, but they instead cognitively categorize business situations more positively. This interpretation leads entrepreneurs to view some situations as positive opportunities. This finding is contradictory to previous research about entrepreneurs' risk-taking propensity, which is thought to be higher among entrepreneurs. In fact they take higher risks but just because they sense opportunities to be more optimistic not because their traits lead them to higher risk-taking. Thus, entrepreneurs' traits do not explain their entrepreneurial behavior but rather their mental information gathering- and processing models - cognitions. Entrepreneurs are not necessarily different from non-entrepreneurs in traits, but they do think differently. Therefore, it is possible to argue that entrepreneurs see business opportunities better than non-entrepreneurs because they cognitively process information related to opportunities in a more "open-way". Palich and Bagby (1995) propose that entrepreneurs may simply frame the same stimuli differently than non-entrepreneurs.

\section{Creativity as Ground for Entrepreneurial Alertness}

The purpose of this chapter is to answer the third sub-question of why individuals behave entrepreneurially alert. This is done by reviewing research on creative behavior of an individual and based on this knowledge by suggesting reasons for entrepreneurial alertness. 
What is creativity? In science there is no general agreement on the definition of creativity. This is due the complex nature of the phenomenon, relative newness of the research of creativity, and different schools viewing creativity from varying perspectives. For example, the humanist school of personality theorists sees creativity as individuals' self-actualizing, while the psychoanalytical school's perspective is that creativity is the result of the preconscious (Woodman, 1983). Cognitive perception, in turn, posits that creativity is a mental style to approaching the environment and resolving problems faced. The social psychological school suggests creativity to be the intellectual activity of persons, influenced strongly by social and environmental conditions (Amabile, 1990, 1997; Amabile, Barsade, Mueller \& Staw, 2005). Finally, the interactionist view combines the before-mentioned perceptions and indicates that creativity should be looked at as the behavior of an organism where situation and organism interact in a complex way (Woodman, Sawyer \& Griffin, 1993; Woodman \& Schoenfeldt, 1990).

Common to all viewpoints is that creativity is basically a question of uniqueness. Creativity is a journey beyond the familiar into the unknown (Csikszentmihalyi, 1988, 1990; Motamedi, 1982). It is the kind of originality out of which imaginative insights are developed. Creativity describes ways of seeing problems not as difficulties but merely as possibilities. It is a chain of thinking in which are connected imagination, inventing, newness, cleverness, insight, intuition, inspiration and illumination (Henry, 1991). Creativity could also be looked on as associations. In that case it is, for instance, a demanding satisfier, conventional stubbornness, unexpected surprise, generous selfishness or disciplined freedom. Amabile (1983) indicates creativity to be regarded as creative when the final product is a novel, appropriate, useful and valuable response to the task at hand, and when the task is heuristic rather than algorithmic. In this study creativity is understood to be, in general, alternatives original to those already existing.

The above promotes the notion that creativity could be divided into realms of individual, process, environment and product (Henry, 1991). From the viewpoint of individual, creativity is the ability of a person. Process view of creativity, in turn, stresses the mental activity of a person. Environment is the external conditions supporting or hindering creativity. Product is the concrete result perceived and valued by others (Henry, 1991: 5-10). Here the angle is more holistic. This study accepts the interactionist view of creativity which realizes that creativity is the complicated behavior of an individual in a given situation (Woodman \& Schoenfeldt, 1990). Thus, creativity is considered to be a phenomenon impossible to view through the above realms separately. Instead, creativity, like business opportunity creation of entrepreneurs, is examined as a unity in which the qualities of an individual, the environmental conditions and the interaction of these have to be explained in order to reach an understanding of creative behavior. Hereafter, the definition of creativity in this study is as follows: Creativity is the ability of an individual to widen and go beyond existing realities.

This ability is a result of interaction between individual qualities and environmental conditions and processed through cognitive processes into concrete, novel and valuable products. Thus, individual-environmental interaction is understood as the base where willingness and ability to behave creatively comes from. Cognitions are seen as mental processes for realizing perceptions and ideas into concrete creative products. The products are judged as artifacts of creativity. The interactionist view of creativity is chosen for the base of this study because interactional psychology provides a strong standpoint for modeling complex behavioral phenomena (Schneider, 1983; Terborg, 1981; Woodman et al., 1993; Woodman \& Schoenfeldt, 1990).

Taking this interactionist view, we can consider what factors affect creativity foundation? According to Woodman and Schoenfeldt (1990) individual qualities that affect creative behavior are constructs of personality traits, cognitive style, motivation, knowledge and antecedent conditions. A fairly stable set of personality trait characteristics have been found to have a positive effect on creativity These are characteristics such as high valuation of esthetic qualities in experience, high energy, broad interests, attraction to complexity, self-confidence, independence of judgment, intuition, autonomy, ability to resolve or accommodate apparently opposite or conflicting traits in one's self concept, and a firm sense of self as creative. Studies on cognitive style, in turn, point out that important cognitive factors for creativity are ability to link elements or ideas flexibly, imagery and verbal fluency, originality, lateral thinking, and complexity (e.g., Basadur \& Thompson, 1986; Noppe, 1985; Quinn, 1980; Suler \& Aizziello, 1987). Motivational factors affecting creativity are, according to Amabile (1990), attitudes toward the task and perceptions of own motivation for undertaking the task. Knowledge builds on domain relevant talent, technical proficiency and factual knowledge (Amabile, 1990). Antecedent conditions include things like reinforcement history, socialization experiences and biographical variables such as gender, family position and birth order (Woodman \& Schoenfeldt, 1990).

Environmental conditions consist of social and contextual influences (Amabile, 1983, 1990; Ciotta, 1987; Getzels \& Jackson, 1961; Klein, 1975; Torrance, 1965; Woodman, 1983). The social psychological school has examined this issue deeply and pointed out that social and contextual matters have to be taken into consideration when trying to understand 
individuals' creative behavior. In accordance with Woodman and Schoenfeldt (1990), the affecting social influences are evaluation, expectations, role models, social facilitation and rewards/punishments. Possible contextual influences are, in turn, culture, physical environment, group/organization climate and task and time constraints.

How then do different inner qualities and environmental conditions affect creativity? Before we go on to describe these, we must consider what different aspects of creativity affect. Thus, if we consider that creativity is realized through a mental process, as the above definition of creativity suggests, there could be found different phases in that process. These phases, after Amabile's (1990) view of creativity, are problem or task presentation, preparation, response generation, response validation and outcome. In the problem or task presentation phase it is a question of an external or internal stimulus to behave in a certain way. The preparation phase includes building up and/or reactivating store of relevant information and response algorithms. Response generation concentrates on searching memory and immediate environment to generate response possibility. The response validation phase is about testing response possibility against factual knowledge and other criteria. In the outcome phase concrete products are validated as success, failure or progress. Creative process, understood as cognition, will be examined in more detail in the next sub-chapter.

Personality dimensions/traits do not have a straightforward effect on the creativity process. Personality is a background factor which strongly influences what kind of cognitive style a person has, how the person is motivated, and how that individual builds up his/her knowledge base. Thus, personality characters beneficial to creativity do not ensure creativity; they only make it possible. Thus, if an individual values highly esthetic qualities, works with high energy, has interest in broad issues, is attracted to complexity, acts self-confidently, makes judgments independently, acts intuitively and autonomously, resolves conflicting traits in one's self concept, and senses self as creative, he/she has a better standpoint for creativity than a person who does not have these personality qualities. Cognitive style affects all creative process phases, but is most influential on response generation phase. Therefore, if an individual has a cognitive style marked by flexibility, fluency, originality, lateral thinking and complexity, he/she can perceive and process information into a more novel solution than a person who is less cognitively talented at creative thinking. Motivation influences the task definition and response generation phases. If motivation is intrinsic, the individual sees the task or problem as attractive and the sparkle for creativity is enlightened. If the motivation base is extrinsic or there is no motivation at all, the individual will finish the task only because he/she has to. Motivation affects response generation so that if the motivation is intrinsic, the creator is willing to create new and original solutions, but if the motivation is extrinsic, the solution is easily conventional and not creative. Knowledge affects preparation and response validation. Knowledge is important for preparation as it helps to identify relevant information. Knowledge also makes it possible to judge whether the solutions invented are good or not. Antecedent conditions influence personality development. Another effect of antecedent conditions is that they help the individual to realize the type of task or problem situation he/she is in - is the situation comfortable, for example.

Environmental conditions mostly affect the individual's motivation. If social issues like evaluation, expectations, role models, social facilitation and rewards/punishments support creativity, intrinsic motivation can develop. This requires that the social environment does not include cruel evaluation, unrealistic expectations, bad role models, lack of social facilitation or punishments. If these affecting factors are present, creativity cannot be expected even though the inner abilities of the individual would support creativity. Contextual influences work just like social influences, but not that strongly. Contextual issues such as culture, physical environment, group/organization climate and task and time constraints should be, in general, open-minded. For instance, the culture should accept dissimilarity, the physical environment should be secure, the group climate could be built on free experimentation and constraints should not be too restrictive. It is important to remember that a creative environment may oppress or release an individuals' inner ability to be creative. Environmental conditions do not create anything concrete, but they surely can kill everything.

The above elements of creativity must be in balance in order to reach creativity. An individual has to be internally creative but the environment has to be supportive also. For example, if the environment is unsupportive, it is difficult to create anything really creative regardless of how creative the person is. The environment simply does not let him be creative. The situation is almost the same, just more dreadful, when the environment is optimal for creativity but the individual does not have abilities to behave creatively. In this case creativity is nearly impossible. The balance can, of course, be whatever, starting from total miss-match to perfect situation. This means that every creative situation is unique. The balance needs to be reached not only between individual and environment but also separately between internal individual qualities and among environmental circumstances. Thus, it is not enough if the individual's motivation, for example, is high but other qualities are poor for creativity. These internal qualities must be in balance too In environmental issues it is exactly the same case. It is not a very supportive situation if a culture, group climate and physical environment are beneficial to creativity but role models, rewarding, evaluation and expectations are against creativity. 
Why are some entrepreneurs alert to business opportunities? It is proposed here that this is due to successful interaction of internal qualities and environmental conditions concerning creativity. They have a supportive creative base for being entrepreneurially alert. This means that their personal histories have supported and taught them to creatively find new businesses. Alertness also means that by their personal traits they are esthetic, energetic, broadly interested, attracted to complexity, confident, independent, intuitive, autonomic, problem-oriented and self-sensed as creative. On the other hand, in their cognitive style they are flexible, fluent, imagery, original, lateral and complex. Alert entrepreneurs are, as well, intrinsically motivated and their knowledge base of the domain is wide and deep. Even though internal qualities are extremely important, environmental conditions make it possible to behave entrepreneurially alerted. If an entrepreneur works, and has worked, in an environment where there is not evaluation and expectations, bad role models, pure social facilitation and punishments, culture and group climate against entrepreneurship, depressive physical surrounding, and task and time constraints restricting flow of ideas, alertness to business opportunities is possible. Therefore, they are able to go beyond perceived information and old ideas/solutions and read market information so that they can combine creative ideas and new information into successful business opportunities. This sub-chapter was about why entrepreneurs are alert. Next sub-chapter will show how entrepreneurial alertness comes into existence.

\section{Creative-Cognitive Model of Entrepreneurial Alertness to Business Opportunities}

The purpose of this chapter is to give an answer to the main research problem of what is alertness to business opportunity from the point of view of cognitive creativity. This is believed to be reached by introducing a creative-cognitive model of entrepreneurial alertness to business opportunities based on the previously presented aspects of why and how and of what kind business opportunities are. For these reasons, a model which focuses on the main elements and practices in entrepreneurial alertness is presented in Figure 1.

\section{$<$ Figure 1 about here $>$}

The following way of thinking is proposed for discussion: Entrepreneurial alertness to business opportunity is the creativity of an individual, consisting of creativity base, creative process and creative product. The creative base consists of interaction of individual qualities and environmental conditions. The creative base makes it possible to behave entrepreneurially alertly so that business opportunities can be found. Therefore, the creative base affects the creative process and the type and quality of the process. The creative process realizes the creative act and points out what kind of results are to be expected. The process is a cognitive activity. The cognitive activity is divided further into the phases of cognitive structure and cognitive process. The cognitive structure has stages of perceiving, conceptualizing and schema building based on information, and the cognitive process stages of problem or task presentation, preparation, response generation, response validation and outcome. Through cognitive activity entrepreneurs process their alertness to concrete business opportunities. These business opportunities are the creative products of this creative-cognitive activity of entrepreneurial alertness. The creative products (business opportunities) are processed into either catalytic, allocative, refining or Omega (recycled) opportunities (Binks \& Vale, 1990).

The creative base is supposed to be the starting point of entrepreneurial alertness. Through interaction of individual qualities and environmental conditions an entrepreneur suggestively has the will and ability to look and find veritable business gaps. This successful interaction of individual and environment in business opportunity identification is understood in this study to be the reason why entrepreneurs are entrepreneurially alert. Good creative base involves: 1) personality of esthetic qualities, high energy, broad interests, complexity, self-confidence, independence of judgment, intuition, autonomy, ability to resolve opposite concepts and a sense of self as creative; 2) cognitive style of flexibility, imagery, fluency, originality, lateral thinking and problem complexity; 3) motivation to be originated from intrinsic factors; 5) wide and deep knowledge of the domain; 6) supportive antecedent conditions; 7) social influences excluding strict evaluation, expectations, bad role models, pure social facilitation and punishments; 8) contextual influences of experimenting culture, safe physical environment, supportive group/ organization climate and flexible task and time constraints; and 9) efficient interaction of these.

The creative process is supposed to be the mental process which makes the business opportunities come true. Through cognitive structure and cognitive process it is suggested that an entrepreneur develop first a schema of the situation and second solve the business problem at hand. The creative process is supposed to be the way entrepreneurial alertness comes into existence. Good schema involves recognizing relevant information, conceptualizing this information to the right visions of demand, supply, capital and knowledge, and scheming these factors into a relevant picture of the whole business situation. Good problem solving includes understanding what the task at hand is, what dimensions this task has, what solutions could be created, what is the best solution and implementation of this solution into an business opportunity.

Creative products, which here are business opportunities, are supposed to be results of creative base and creative process. 
Thus, business opportunities are what come of entrepreneurial alertness. Business opportunities could be, at least in this case, catalytic, allocative, refining or recycled (Omega). Catalytic opportunities are the most innovative because these are both creatively radical and based on market demand. Allocative opportunities are the second-most innovative, as those are based on market demand even though creative radicalness is smaller. Refining and recycled opportunities are based more on an internal vision of an entrepreneur or on the situation (for example, recycled resources released based on bankruptcies) than on market need and/or originality.

\section{Discussion and Implications}

Much research has shown that a creative-cognitive approach makes a difference in an individual's existing reality (e.g., Amabile, 1990; Woodman \& Schoenfeldt, 1990). Creativity thus refers to original, novel and unexpected results. Creativity is the capability and the force creating something better (Henry, 1991). Creativity is needed when situations and problems are complex, new and the old solutions do not work anymore. Hence, it is possible to propose business opportunities to be creative products of entrepreneurs and looked at as creativity because creating them requires processing complex information into original and unexpected results. The above is also supported by Gilad (1984) who has suggested business opportunities to be consequences of creative behavior and that there is always creativity in present when new businesses are to emerge. Creativity could also be found in the work of Schumpeter (1934) since he has stressed creative destruction to be a crucial part of finding new business opportunities. Leibenstein (1961) and Kirzner (1979), as well, have emphasized the importance of the creative element in entrepreneurial activity. In addition, Baumol (1993) has suggested that the innovative element of entrepreneurship should be studied as the creativity of an individual. Therefore, alertness to business opportunities is examined in this study as the creative behavior of entrepreneurs.

Entrepreneurship as creativity is not simple and logical (unfortunately or luckily depending on the point of view), because an opportunity needs creative insight and sensitivity concerning how to combine all fragmented information. If it were only the arrangement of information, everyone would notice his or her opportunity. However, this is not the case. For example, with a jigsaw puzzle, we know we are putting together a puzzle and that every piece has its own place. By diligently and systematically trying the pieces, the puzzle is solved. An entrepreneurial opportunity is not this kind of puzzle. Instead of a puzzle, imagine a situation where you have some pieces of sorts, but have no concept of what you should do with them. You have to work based on your own creativity, conceive what it is about, work out what the pieces are linked to, conceive a solution, conceive what way the pieces bring about a solution, and understand what is the trick of it all is, so that the next time you are not "so out of it" as you were this time. An opportunity is more about creating a meaning based on scattered and ambiguous information, rather than deriving a decision within a limited "decision of space" and being based on exact information.

\section{References}

Amabile, T. (1983). The social psychology of creativity: A componential conceptualization. Journal of Personality and Social Psychology, 45(2), 357-376. http://dx.doi.org/10.1037/0022-3514.45.2.357

Amabile, T. (1990). Within you, without you: The social psychology of creativity, and beyond. In: Theories of Creativity 61-91. Eds. Runco, M. \& Albert, R. Sage Publications, California.

Amabile, T. (1997). Motivating creativity in organizations: On doing what you love and loving what you do. California Management Review, 40(1), 39-59.

Amabile, T., Barsade, S., Mueller, J. \& Staw, B. (2005). Affect and creativity at work. Administrative Science Quarterly, 50(3), 367-403. http://dx.doi.org/10.2189/asqu.2005.50.3.367

Anokhin, S., Wictor, J., \& Autio, E. (2009). Operationalizing opportunities in entrepreneurship research: Use of data envelopment analysis. Small Business Economics, in press. http://dx.doi.org/10.1007/s11187-009-9227-1.

Baron, R. (2004). The cognitive perspective: A valuable tool for answering entrepreneurship’s basic "why” questions. Journal of Business Venturing, 19(2), 221-239. http://dx.doi.org/10.1016/S0883-9026(03)00008-9

Basadur, M. \& Thompson, R. (1986). Usefulness of the ideation principle of extended effort in real world professional and managerial creative problem solving. Journal of Creative Behavior, 20, 23-24.

Baumol, W. (1993). Formal entrepreneurship theory in economics: Existence and bounds. Journal of Business Venturing, 8(4), 197-210. http://dx.doi.org/10.1016/0883-9026(93)90027-3

Bazerman, M. (1990). Judgement in Managerial Decision-Making. John Wiley and Sons, New York.

Binks, M. \& Vale, P. (1990). Entrepreneurship and Economic Change. McGraw-Hill Book Company (UK) Limited, 
Maidenhead.

Bull, I. \& Willard, G. (1993). Towards a theory of entrepreneurship. Journal of Business Venturing, 8, $183-195$. http://dx.doi.org/10.1016/0883-9026(93)90026-2

Busenitz, L. \& Barney, J. (1997). Differences between entrepreneurs and managers in large organizations: Biases and heuristics in strategic decision-making. Journal of Business Venturing, 12, 9-30. http://dx.doi.org/10.1016/S0883-9026(96)00003-1

Busenitz, L. \& Lau, C-M. (1996). A cross-cultural cognitive model of new venture creation. Entrepreneurship Theory and Practice, 20(4), 25-39.

Bygrave, W. (1993). Theory building in the entrepreneurship paradigm. Journal of Business Venturing, 8, $255-280$. http://dx.doi.org/10.1016/0883-9026(93)90031-Y

Carree, M. \& Thurik, R. (1994). The dynamics of entry, exit and profitability: An error correction approach for the retail industry. Small Business Economics, 6(2), 107-116. http://dx.doi.org/10.1007/BF01065183

Cheah, H. (1990) Schumpeterian and Austrian entrepreneurship: Unity within duality. Journal of Business Venturing, 5(6), 341-347. http://dx.doi.org/10.1016/0883-9026(90)90010-Q

Ciotta, P. (1987). The anatomy of creative corporate culture. Journal of Creative Behavior, 21, 145-152.

Cooper, A., Folta, T. \& Woo, C. (1995). Entrepreneurial information search. Journal of Business Venturing, 10, $107-120$. http://dx.doi.org/10.1016/0883-9026(94)00022-M

Csikszentmihalyi, M. (1988). Society, culture and person: A systems view of creativity. In: The Nature of Creativity 325-339. Ed. Sternberg, R.J. Cambridge University Press: Cambridge, UK.

Csikszentmihalyi, M. (1990). Flow: The Psychology of Optimal Experience. HarperCollins, New York, USA.

Fischoff, B., Slovic, P. \& Lichtenstein, S. (1977). Knowing with uncertainty: The appropriateness of extreme confidence. Journal of Experimental Psychology: Human Perception and Performance, 3, 552-564. http://dx.doi.org/10.1037/0096-1523.3.4.552

Gaglio, C.M. \& Katz J. (2001). The psychological basis on opportunity identification: Entrepreneurial alertness. Small Business Economics, 16(2), 95-111. http://dx.doi.org/10.1023/A:1011132102464

Gaglio, C.M. (2004). The role of mental simulations and counterfactual thinking in the opportunity identification process. Entrepreneurship Theory and Practice, 28(6), 533-552. http://dx.doi.org/10.1111/j.1540-6520.2004.00063.x

Getzels, J. \& Jackson, P. (1961). Family environment and cognitive style: A study of the sources of highly intelligent and highly creative adolescents. American Sociological Review, 26, 351-359. http://dx.doi.org/10.2307/2090662

Gilad, B. (1984). Entrepreneurship: The issue of creativity in the market place. Journal of Creative Behavior, 18(3), 151-161.

Hebert, R. \& Link, A. (1988). The Entrepreneur. Mainstream Views and Radical Critique. Preager, New York.

Henry, J. (1991). Making sense of creativity. In: Creative Management, 3-11. Ed. Henry, J. Sage Publications, London.

Kahneman, D. (2003). Maps of bounded rationality: Psychology for behavioral economics. American Economic Review, 93 (5): 1449-1475. http://dx.doi.org/10.1257/000282803322655392

Kahneman, D., Tversky, A. \& and Slovic, P. (1982). Judgment under Uncertainty: Heuristics \& Biases. Cambridge University Press, Cambridge, UK.

Kaish, S., \& Gilad, B. (1991). Characteristics of opportunities search of entrepreneurs versus executives: Sources, interests, general alertness. Journal of Business Venturing, 6, 45-61. http://dx.doi.org/10.1016/0883-9026(91)90005-X

Kirzner, I. (1979). Perception, Opportunity, and Profit: Studies in the Theory of Entrepreneurship. University Chicago Press, Chicago.

Kirzner, I. (1981). Competition and Entrepreneurship. University Chicago Press, Chicago.

Kirzner, I. (1997). Entrepreneurial discovery and the competitive market process: An Austrian approach. Journal of Economic Literature, 35(1), 60-85.

Klein, P. (1975). Effects of open vs. structured teacher-student interaction on creativity of children with different levels $\begin{array}{lllll}\text { of anxiety. } & \text { Psychology } & \text { in }\end{array}$ 
http://dx.doi.org/10.1002/1520-6807(197507)12:3<286::AID-PITS2310120307>3.0.CO;2-X

Krueger, N. (2005). The cognitive psychology of entrepreneurship. In: Handbook of Entrepreneurship Research. International Handbook Series on Entrepreneurship, 1(3), 105-140. Eds. Acs, Z. \& Audretsch, D. Springer, New York. http://dx.doi.org/10.1007/0-387-24519-7_6

Leibenstein, H. (1966). Allocative efficiency vs. ”X-efficiency". American Economic Review, 56(3), $392-415$. HTTP://DX.DOI.ORG/10.1126/science.151.3712.867-a

Manimala, M. (1992). Entrepreneurial heuristics: A comparison between high PI (pioneering-innovative) and low PI ventures. Journal of Business Venturing, 7(6), 477-504. http://dx.doi.org/10.1016/0883-9026(92)90021-I

Martello, W. (1994). Developing creative business insights: Serendipity and its potential in entrepreneurship. Entrepreneurship and Regional Development, 6, 239-258. http://dx.doi.org/10.1080/08985629400000014

Mayer, R.E. (1992). Thinking, Problem Solving, and Cognition. W.H. Freeman and Company, New York.

Motamedi K. (1982). Extending the concept of creativity. The Journal of Creative Behavior, 16(2), 75-88.

Nisbett, R. \& Ross, L. (1980). Human Inference: Strategies and Shortcomings of Social Judgements. Prentice-Hall, Englewood Cliffs, NJ.

Noppe, L. (1985). The relationship of formal thought and cognitive styles to creativity. Journal of Creative Behavior, 19, 88-96.

Oswald, M. \& Stefan, G. (2004). Confirmation bias. In: Handbook on Fallacies and Biases in Thinking, Judgement and Memory 79-96. Ed. Pohl, R. Psychology Press, New York

Palich, L. \& Bagby, D.R. (1995). Using cognitive theory to explain entrepreneurial risk-taking: challanging conventional wisdom. Jounal of Business Venturing, 10; 425-438. http://dx.doi.org/10.1016/0883-9026(95)00082-J

Quinn, E. (1980). Creativity and cognitive complexitiy. Social Behavior and Personality, 8, $213-215$. http://dx.doi.org/10.2224/sbp.1980.8.2.213

Schneider, B. (1983). Interactional psychology and organizational behavior. In: Research in Organizational Behavior 1-31. Eds. Cummings, L. \& Staw, B.. JAI Press, Greenwich.

Schneider, D. (1995). Attribution and social cognition. In: Social psychology 38-56. Eds. Argyle, M. \& Colman, A.M. Longman Publishing, New York.

Schumpeter, J. (1934). The Theory of Economic Development. Harvard University Press, Cambridge, MA.

Shane, S. \& Venkataraman, S. (2000). The promise of entrepreneurship as a field of research. Academy of Management Review, 25(1), 217-226.

Shepherd, D. \& DeTienne, D. (2005). Prior knowledge, potential financial reward, and opportunity identification. Entrepreneurship Theory and Practice, 29(1), 91-112. http://dx.doi.org/10.1111/j.1540-6520.2005.00071.x

Suler, J. \& Aizziello, J. (1987). Imagery and verbal processes in creativity. Journal of Creative Behavior, 21, 1-16.

Terborg, J. (1981). Interactional psychology and research on human behavior in organizations. Academy of Management Review, 6, 569-576. http://dx.doi.org/10.2307/257635

Torrance, E.P. (1965). Rewarding Creative Behavior: Experiments in Classroom Creativity. Prentice-Hall, Englewood Cliffs, NJ.

Tversky, A. \& Kahneman, D. (1971). The belief in the ”law of small numbers”. Psychological Bulletin, 76, 105-110. http://dx.doi.org/10.1037/h0031322

Tversky, A. \& Kahneman, D. (1974). Judgement under uncertainty: heuristics and biases. Science, 185, $1124-1131$. http://dx.doi.org/10.1126/science.185.4157.1124

Woodman, R. \& Schoenfeldt, L. (1990). An interactional model of creative behavior. Journal of Creative Behavior, 24(4), 279-289. http://dx.doi.org/10.2307/258761

Woodman, R. (1983). Creativity as a construct in personality theory. Journal of Creative Behavior, 15:1, 43-65.

Woodman, R., Sawyer, J. \& Griffin, R. (1993). Toward a theory of organizational creativity. Academy of Management Review, 18, 293-321.

Yu, T. (2001). Entrepreneurial alertness and discovery. Review of Austrian Economics, 14(1), 47-63. http://dx.doi.org/10.1023/A:1007855505727 
Zahra, S., Korri, J.S., Yu, J., 2005. Cognition and international entrepreneurship: Implications for research on international opportunity recognition and exploitation. International Business Review, 14, 129-146. http://dx.doi.org/10.1016/j.ibusrev.2004.04.005

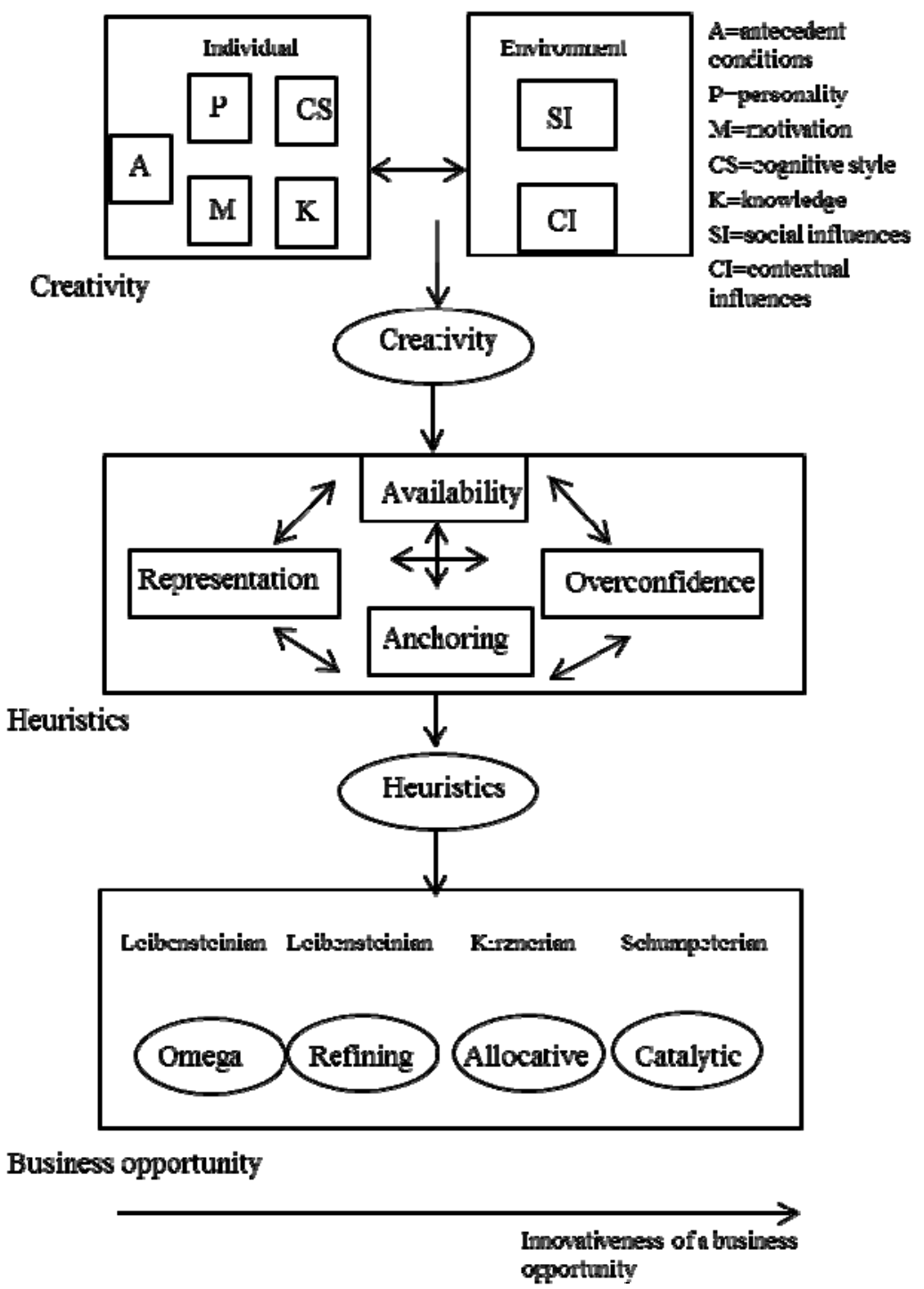

Figure 1. Creative-Cognitive Model of Entrepreneurial Alertness to Business Opportunities 